\title{
PENGARUH KONFLIK PERAN DAN STRES KERJA TERHADAP KOMITMEN ORGANISASI DI RUMAH SAKIT TK IV SALAK, BOGOR
}

\author{
Sri Rulestri L.H. \\ Henry Eryanto**
}

\begin{abstract}
The study aims to determine whether there is effect role conflict and work stress to organization commitment at Rumah Sakit Tk IV Salak Bogor and also to get a valid and reliable data or fact, to prove it. The research has been done during April 2013. The method of this research is survey. The population research was all nurse of Rumah Sakit Tk IV Salak Bogor as much as 110 nurses. And the sample used as many 40 married women nurses by using simple random sampling. The result reveals that there is effect between role conflict to organization commitment, and also work stress to organiza-tion commitment, and then there is effect between role conflict and work stress to organization commitment of nurses Rumah Sakit Tk IV Salak, Bogor.
\end{abstract}

Keywords:role conflict, work stress, organization commitment

\section{PENDAHULUAN}

Persaingan bisnis antara perusahaan semakin besar. Setiap perusahaan atau organisasi dituntut untuk meningkatkan kualitas produk yang dihasilkannya. Apabila perusahaan tersebut tidak dapat meningkatkan kualitas produk atau setidaknya mempertahankannya, maka kelangsungan hidup

\footnotetext{
Sri Rulestri L.H adalah alumni Fakultas Ekonomi Universitas Negeri Jakarta ** Henry Eryanto adalah Dosen Fakultas Ekonomi Universitas Negeri Jakarta
}

perusahaan kemungkinan besar tidak dapat bertahan lama. Kualitas produk yang dihasilkan oleh sebuah perusahaan dapat ditingkatkan jika perusahaan dapat mengoptimalkan seluruh sumber daya yang dimilikinya. Salah satu sumber daya yang sangat penting yang dimiliki oleh perusahaan adalah sumber daya manusia.

Dalam kompetisi bisnis saat ini, komitmen pada organisasi sangat dibutuhkan. Komitmen organisasi adalah rasa memiliki terhadap 
perusahaan yang dicerminkan dari bagaimana seorang karyawan terlibat dan berpartisipasi dalam pekerjaan-pekerjaan yang ada di perusahaan termasuk dalam pengambilan keputusan..

Tetapi pada kenyataannya untuk untuk memperoleh karyawan yang memiliki komitmen organisasi yang tinggi bukanlah hal yang mudah.

Faktor yang dapat mempengaruhi komitmen organisasi adalah konflik peran. Konflik peran seringkali dialami oleh karyawan, karena peran ganda yang ia laksanakan, baik di dalam perusahaan, keluarga dan perannya di masyarakat. terkadang tuntutan yang berbeda dari setiap peran itu malah membuat karyawan merasa tertekan dan merasa tidak betah bekerja di perusahaan tersebut, sehingga pada akhirnya dapat menurunkan komitmennya pada perusahaan.

Stres kerja juga dapat mempengaruhi komitmen organisasi karyawan. Karyawan yang mengalami stres kerja yang relatif sering dapat menyebabkannya jenuh bekerja atau bahkan berniat untuk meninggalkan perusahaannya. Hal ini dapat menurunkan komitmen pada perusahaan.
Penelitian ini bertujuan untuk membuktikan adanya:

1. Pengaruh konflik peran terhadap komitmen organisasi di Rumah Sakit Tk IV Salak, Bogor

2. Pengaruh stres kerja terhadap komitmen organisasi di Rumah Sakit Tk IV Salak, Bogor

3. Pengaruh konflik peran dan stres kerja terhadap komitmen organisasi di Rumah Sakit Tk IV Salak, Bogor

\section{DESKRIPSI TEORITIS Komitmen Organisasi}

Komitmen organisasi seseorang biasanya dikaitkan dengan kesetiaannya terhadap organisasi. Akan tetapi, para ahli tidak hanya mengartikan komitmen organisasi sebagai kesetiaan, melainkan ada beberapa hal yang tercakup di dalamnya.

Gibson, Ivancevich \& Donelly dalam Yasmin Umar Assegaf (2005:91) bahwa "komitmen sebagai lingkup identifikasi, keterlibatan dan loyalitas yang diekspresikan oleh seseorang terhadap organisasinya" Komitmen organisasi muncul karena keterlibatan karyawan pada organisasi sehingga lebih mengenal organisasinya dan memiliki kesetiaan pada organisasi.

Sama halnya yang dikemukakan McShane (2009:77), 
yaitu "organizational commitment refers to the employee's emotional attachment to, identification with, and involvement in a particular organization" bahwa komitmen organisasi merujuk pada perasaan memiliki karyawan, identifikasi, dan keterlibatan dalam sebuah organisasi tertentu.

Aranya dan Ferris dalam Suparwati (2005:50) bahwa "komitmen organisasional menyangkut 3 sikap yaitu rasa mengidentifikasi dengan tujuan organisasi, rasa keterlibatan dengan tugas organisasi, dan rasa kesetiaan kepada organisasi"

Menurut John W Newstrom (2007:207) " organizational commitment or employee loyality is the degree to which an employee identifies with the organization and want to continue actively participating in it". Komitmen organisasi dalam hal kesetiaan karyawan adalah tingkat yang mengidentifikasikan seorang karyawan dengan organisasi dan keinginan untuk ikut serta aktif di dalam organisasi.

Mowday dalam Yasmin Umar Assegaf (2005:92) bahwa: "Komitmen organisasi mengacu pada tingkat keterlibatan individu dengan keorganisasiannya yang dikarakteristikkan dengan 3 faktor, yaitu penerimaan dan kepercayaan akan tujuan dan nilai yang dianut organisasi, kesediaan untuk menggunakan keseluruhan kemampuan untuk kemajuan organisasi, dan keinginan untuk tetap berada atau bekerja dalam organisasi"

Gibson (2005:184) juga berpendapat bahwa "komitmen organisasi adalah keterlibatan seorang karyawan yang menunjukkan adanya rasa pengidentifikasian dengan tujuan perusahaan, perasaan keterlibatan dalam perusahaan dan rasa kesetiaan"

Konflik peran dan stres kerja dapat mempengaruhi tingkat komitmen organisasi yang dimiliki seseorang. Jika seorang individu tidak memiliki permasalahan di dalam organisasi, maka ia akan merasa bekerja di organisasi tersebut, yang berarti ia memiliki komitmen yang cukup tinggi pada organisasi. Seperti yang dikemukakan Ahmad Usman (2011:207) bahwa "The result of hypotheses tests show that role ambiguity leads towards role conflict and work stress is negatively associated with job satisfaction and organizational commitment". Hasil dari tes hipotesis menunjukan bahwa ketidakjelasan peran mengarah kepada konflik peran dan stres kerja berhubungan negatif 
dengan kepuasan kerja dan komitmen organisasi.

Hal senada juga dikemukakan oleh Yasmin Assegaf (2005: 105) dalam penelitiannya bahwa "secara serentak konflik peran dan stres kerja berpengaruh terhadap komitmen organisasi"

Dengan demikian, maka dapat disimpulkan bahwa komitmen organisasi adalah identifikasi, keterlibatan dan kesetiaan seseorang terhadap organisasi. Identifikasi (penerimaan terhadap tujuan dan nilai-nilai organisasi), keterlibatan (kesediaan berusaha dengan maksimal untuk kemajuan organisasi), dan kesetiaan (keinginan untuk menetap di organisasi).

\section{Konflik Peran}

Konflik peran yang dialami oleh seseorang dapat menimbulkan rasa tidak nyaman pada dirinya dalam menjalankan perannya dalam organisasi.

Menurut Richard L Daft (2006: 311), "konflik peran adalah tuntutan-tuntuntan yang tidak sejalan dari peran-peran yang berbeda"

Jerald Greenberg (2003:221), "konflik peran adalah sebuah situasi ketika seseorang dihadapkan beberapa pertentangan kewajiban yang mereka miliki" Konflik peran terjadi apabila adanya pertentangan antara dua peran yang berbeda yang dijalankan oleh seseorang.

Menurut Wood dalam Budi Eko (2005:409)" konflik peran terjadi ketika seseorang dalam sebuah peran tertentu tidak dapat merespon harapan-harapan dari satu atau lebih anggota dari seperangkat peran"

Tidak jauh berbeda dengan pendapat Kopelman, Greenhaus and Connolly dalam Michael Glissmeyer, "role conflict has also been defined as the extent to which a person experiences pressures within one role that are incompatible with pressures that arise within another role" bahwa konflik peran sebagai tingkatan dimana seseorang mengalami tekanan yang muncul dari peran yang lain.

Konflik peran dapat dialami oleh siapapun yang memiliki lebih dari satu peran yang dijalankan secara bersamaan. Akan tetapi, konflik peran biasanya dialami oleh wanita yang bekerja, seperti yang dikemukakan oleh Kapur dalam Sunita Malhotra (2005:38) bahwa " women who choose to combine marriage with career face almost a situation of normlessness and they hardly know how to apportion time and resources between these two major responsibilities. This make them experience great conflict, 
tension and strain" Dapat diartikan bahwa wanita yang memilih mengkombinasikan pernikahan dengan karir menghadapi hampir semua dari situasi ketidakteraturan dan mereka sulit mengetahui bagaimana membagi secara adil waktu dan sumber penghasilan antara dua tanggungjawab besar ini. Ini membuat mereka mengalami konflik besar dan ketegangan.

Konflik peran dapat mempengaruhi komitmen seseorang pada organisasi, seperti yang dikemukakan oleh Khan, Jackson and Schuler dalam Yasmin (2005:104) "konflik peran mempunyai dampak negatif terhadap perilaku karyawan, seperti timbulnya ketegangan kerja, peningkatan perputaran kerja, penurunan kepuasan kerja, penurunan komitmen pada organisasi dan penurunan kinerja keseluruhan"

$$
\text { Jadi dapat disimpulkan }
$$

bahwa konflik peran suatu kondisi adanya pertentangan dan tekanan dari peran lain yang sedang dijalankan seseorang bersamaan. Pertentangan (tuntutan, harapan dan kewajiban), tekanan (dari peran lain).

\section{Stres Kerja}

Stres merupakan salah satu masalah yang mungkin akan dihadapi oleh setiap orang dalam kehidupan bekerja dan yang harus segera diatasi. Stres dapat terjadi di lingkungan kerja maupun di luar lingkungan kerja.

Menurut Husein Umar (2010:44) "stres didefinisikan sebagai suatu kondisi ketegangan yang memengaruhi emosi, proses berpikir dan kondisi seorang pekerja" Stres adalah suatu keadaan dimana seseorang merasa tegang dan tertekan karena berbagai faktor atau masalah yang dihadapinya, mungkin di lingkungan kerja ataupun di luar lingkungan kerja dan perasaan tegang dan tertekan ini pun akan mempengaruhi emosinya, keadaan fisik serta cara berpikir dari seseorang.

Menurut Ivancevich, Gibson, Donelly (2009:70) bahwa "stres sebagai suatu tanggapan penyesuaian yang dilatarbelakangi oleh perbedaan individu atau proses psikologi/fisik yang berlebihan kepada seseorang"

Menurut Cox dalam Lina Anatan (2009:73) "efek yang ditimbulkan oleh work stress,yaitu:

a. physical problem meliputi penyakit dan gangguan kesehatan, seperti kadar gula naik, denyut jantung naik, tekanan darah naik, mulut kering, berkeringat, penyakit jantung dan kolesterol tinggi. 
b.psychological problem yaitu adanya reaksi-reaksi yang biasanya muncul meliputi kesulitan berkonsentrasi dan berpikir jernih yang diikuti dengan meningkatnya rasa mudah marah dan kesulitan untuk relaks, perasaan gelisah, kelesuan, kebosanan, kemurungan, depresi, kekecewaan (frustasi), harga diri yang rendah, kegelisahan, dan perasaan terpencil"

Edelmann dalam Lina Anatan (2009:73), "efek yang ditimbulkan oleh work stress yaitu behavioral problem meliputi penarikan diri dari lingkungan yang disebabkan oleh adanya kesulitan menjalin hubungan dengan orang lain, penggunaan alcohol, rokok, obat-obat penenang yang bertujuan untuk mengurangi ketegangan"

Fontana dalam Lina Anatan (2009:73), "dampak stres adalah organizational problem meliputi tingkat kepuasan kerja menurun, komitmen dan loyalitas terhadap organisasi menurun dan produktivitas kerja menurun, sehingga mengakibatkan tingkat absensi dan turnover meningkat"

Jadi dapat disimpulkan bahwa stres kerja adalah meliputi reaksi fisik, psikologi dan perilaku yang timbul karena adanya masalah di tempat kerja.

\section{Kerangka Berpikir}

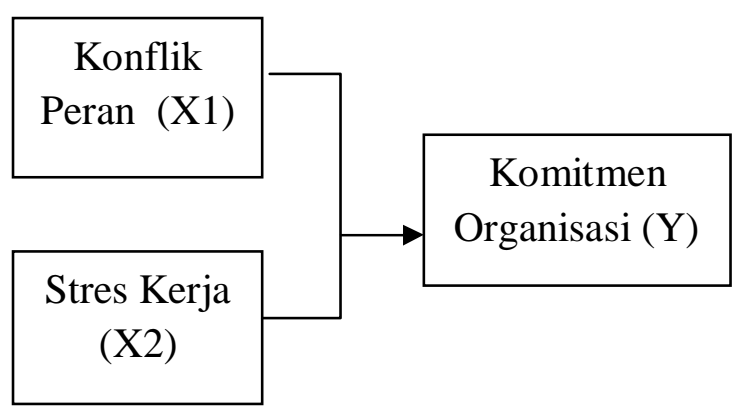

\section{Perumusan Hipotesis}

Berdasarkan kerangka berpikir diatas, maka dapat dirumuskan hipotesisnya adalah:

1. Terdapat pengaruh antara konflik peran terhadap komitmen organisasi

2. Terdapat pengaruh antara stres kerja terhadap komitmen organisasi

3. Terdapat pengaruh antara konflik peran dan stres kerja terhadap komitmen organisasi

\section{METODE PENELITIAN}

Penelitian ini menggunakan metode survey dengan pendekatan korelasional guna mengetahui derajat pengaruh antara konflik peran dan stres kerja sebagai variabel $X \quad$ (variabel yang mempengaruhi) dan komitmen organisasi sebagai variabel $Y$ (variabel yang dipengaruhi).

Populasi dalam penelitian ini adalah perawat Rumkit Tk IV Salak Bogor yang berjumlah 110 orang. 
Karena keterbatasan peneliti untuk meneliti semua perawat, maka diambil populasi terjangkau yaitu perawat wanita dan yang sudah menikah yaitu berjumlah 45 orang. Berdasarkan tabel Isaac dan Michael jumlah sampel yang diambil adalah 40 orang dengan tingkat kesalahan sebesar $5 \%$.

Teknik pengambilan sampel yang digunakan dalam penelitian ini adalah teknik sampel acak sederhana (simple random sampling) melalui undian, dimana setiap nama perawat yang dijadikan sampel ditulis pada kertas gulungan kecil dan kemudian dimasukkan ke dalam kotak, lalu diundi sampai keluar 40 nama sebagai sampel.

\section{Definisi Operasional}

a. Komitmen organisasi merupakan data primer diukur dengan teknik kuesioner model skala Likert yang mencerminkan indikator antara lain: identifikasi (penerimaan terhadap tujuan dan nilai-nilai organisasi), keterlibatan (kesediaan berusaha dengan maksimal untuk kemajuan organisasi), dan kesetiaan (keinginan untuk menetap di organisasi).

b. Konflik peran adalah merupakan data primer yang diukur dengan teknik kuesioner skala Likert yang mencerminkan indikator, antara lain: adanya pertentangan (tuntutan, harapan, kewajiban) dan tekanan (dari peran lain) yang sedang dijalankan.

c. Stres kerja merupakan data primer diukur dengan teknik kuesioner dengan skala Likert yang mencerminkan indikator meliputi reaksi fisik (rasa panas dingin, berkeringat, denyut jantung naik), reaksi psikologi (gelisah, kemurungan, sulit berkonsentrasi, dan mudah marah).dan reaksi perilaku (penarikan diri).

\section{HASIL DAN PEMBAHASAN}

1. Uji Persyratan Analisa

a. Uji Normalitas

Uji normalitas digunakan untuk mengetahui apakah populasi data berdistribusi normal ataukah tidak. Dalam penelitian ini, pengujian dilakukan dengan menggunakan uji KolmogorovSmirnov dengan menggunakan SPSS 17.0 dengan tingkat signifikansi $5 \%$ atau 0,05 . Kriteria pengambilan keputusannya adalah jika nilai signifikansi > 0,05 maka data berdistribusi normal.

Berdasarkan hasil pengujian normalitas dapat diketahui signifikansi nilai konflik peran $\left(X_{1}\right)$ sebesar 0,200 , stres kerja $\left(X_{2}\right)$ sebesar 0,200 dan komitmen 
organisasi (Y) sebesar 0,200. Dari ketiga variabel diatas semuanya memiliki tingkat signifikansi diatas 0,05, ini menunjukkan berarti data memiliki distribusi normal.

\section{b. Linearitas}

Uji linieritas ini bertujuan untuk mengetahui apakah dua variabel secara signifikansi mempunyai hubungan yang linier atau tidak. Dalam uji linieritas ini digunakan Test of Liniearity dengan taraf signifikansi 0,05. Dua variabel dikatakan memiliki hubungan yang linier bila nilai signifikansi pada output Linearity $<0,05$. Hasil output perhitungan uji Linearitas dapat dilihat pada Tabel $\mathbf{2}$ dan Tabel 3.

Berdasarkan hasil pengujian linearitas dapat diketahui bahwa nilai liniearitasnya antara konflik peran terhadap komitmen organisasi adalah sebesar 0,000, dan antara stres kerja terhadap komitmen organisasi adalah sebesar 0,002 dimana nilai tersebut memiliki signifikan kurang dari 0,05, sehingga dapat disimpulkan bahwa variabel konflik peran dan stres kerja serta komitmen organisasi memiliki hubungan yang linier.

\section{Uji Asumsi Klasik}

\section{a. Uji Multikolinearitas}

Uji ini digunakan untuk menguji apakah model regresi ditemukan adanya korelasi antar variabel independen. Metode pengujian yang biasa digunakan yaitu dengan melihat nilai Variance Inflation Factor (VIF) dan Tolerance pada model regresi. Dengan asumsi semakin kecil nilai Tolerance dan semakin besar nilai VIF maka akan semakin mendekati terjadinya masalah multikolinearitas. Kriteria pengujian yang digunakan jika nilai Tolerance > 0,1 dan VIF < 10 maka tidak terjadi multikolinearitas. Hasil output tabel multikolinearitas dapat dilihat pada Tabel 4.

Hasil output dalam tabel diatas dapat diketahui bahwa kedua variabel yakni konflik peran dan stres kerja memiliki nilai Tolerance $0,890>0,1$ dan nilai VIF $1.124<$ 10, maka dapat disimpulkan bahwa model regresi dari kedua variabel tersebut tidak terjadi multikolinearitas.

\section{b. Uji Heterokedastisitas}

Uji ini digunakan untuk menguji apakah dalam model regresi berganda terjadi ketidaksamaan varian dari residual pada satu pengamatan kepengamatan yang lain. Dalam mendeteksi apakah terjadi heterokedastisitas ataukah tidak digunakan metode uji korelasi Rank Spearman, dimana analisis dilakukan antara absolut residual 
hasil regresi dengan masing-masing variabel independen. Kriteria pengujian yang diambil adalah jika nilai signifikansi hasil korelasi lebih kecil dari < 0,05 (5\%) maka persamaan regresi tersebut mengandung heterokedastis. Hasil output dapat dilihat pada Tabel 5.

Hasil output pada tabel 5 menunjukan bahwa korelasi kedua variabel dengan absolut residual nilai signifikansinya yakni konflik peran memiliki nilai signifikan 3,30 dan stres kerja memiliki nilai signifikan 0,331 sehingga lebih besar daripada 0,05 , ini berarti model regresi yang diuji tidak ada heterokedastisitas.

\section{Regresi Berganda}

Model persamaan regresi berganda dapat dilihat pada Tabel 6 diperoleh hasil sebagai berikut:

$\hat{Y}=a+b_{1} X_{1}+b_{2} X_{2}$

$\hat{Y}=105,003-0,494 X_{1}-0,288 X_{2}$

Nilai $\mathrm{a}=$ angka konstan sebesar 105,003, yang artinya jika konflik peran dan stres kerja nilainya 0 , maka komitmen organisasi nilainya sebesar 105,003.

Selanjutnya, dilihat dari koefisien regresi variabel konflik peran $\left(b_{1}\right)$ sebesar $-0,494$ dan koefisien regresi variabel stres kerja $\left(b_{2}\right)$ sebesar -0,288 yang diartikan jika konflik peran dan stres kerja mengalami kenaikan, maka komitmen organisasi akan mengalami penurunan sebesar angka yang dihasilkannya.

\section{Uji Hipotesis}

a. Uji $\mathbf{F}$

Uji F atau uji koefisien regresi secara bersama-sama, digunakan untuk mengetahui hubungan variabel bebas secara bersamasama terhadap variabel terikat. Kriteria pengujian yang diambil adalah jika $F_{\text {hitung }}>F_{\text {tabel }}$ maka $\mathrm{HO}$ ditolak dan $\mathrm{F}_{\text {hitung }}<\mathrm{F}_{\text {tabel, }}$ maka $\mathrm{HO}$ diterima dengan menggunakan tingkat signifikansi 0,05. Hasil output uji $F$ dapat dilihat pada Tabel 7.

Dengan menggunakan $\mathrm{F}_{\text {tabel, }} \mathrm{a}$ $=0,05 \%, \mathrm{df} 1=2 ; \mathrm{df} 2=37$, maka hasil $F_{\text {tabel }}$ yang diperoleh adalah 3,26. Berdasarkan output perhitungan dari tabel ANOVA diatas, $F_{\text {hitung }}$ yang diperoleh adalah sebesar 21,483 dengan signifikansi 0,05 . Ini menunjukan $F_{\text {hitung }}>F_{\text {tabel, }}$ yakni $21,483>3,26$, maka $\mathrm{H}_{0}$ ditolak, yang artinya konflik peran dan stres kerja mempunyai pengaruh bersama-sama secara terhadap komitmen organisasi.

\section{b. Uji t}

Untuk mengetahui apakah koefisien regresi signifikan atau tidak kita akan menggunakan uji $\mathrm{t}$ untuk menguji signifikansi 
konstanta. Uji ini digunakan untuk mengetahui pengaruh variabel independen secara parsial terhadap variabel dependen. Kriteria pengujian $\mathrm{H}_{0}$ diterima jika t hitung $\leq$ t tabel, jadi $\mathrm{H}_{0}$ diterima dan $\mathrm{H}_{0}$ ditolak $\mathrm{t}$ hitung $>\mathrm{t}$ tabel, jadi $\mathrm{H}_{\mathrm{o}}$ ditolak. Dapat dilihat pada Tabel 8.

Nilai $t_{\text {tabel }}$ yang diperoleh adalah 2,028. Nilai thitung untuk variabel konflik peran yang diperoleh dari tabel ANOVA adalah 4.512, maka $\mathrm{H}_{0}$ ditolak dan $\mathrm{H}_{\mathrm{a}}$ diterima, dimana nilai $t_{\text {hitung }}>$ $t_{\text {tabel }}(4.512>2,028)$, konflik peran $\left(X_{1}\right)$ berpengaruh terhadap komitmen organisasi $(Y)$.

Sedangkan untuk nilai thitung variabel stres kerja yang diperoleh dari tabel ANOVA adalah 2.988, maka, dimana nilai $t_{\text {hitung }}>t_{\text {tabel }}$ $(2.988>2,028)$, stres kerja $\left(\mathrm{X}_{2}\right)$ berpengaruh dengan komitmen organisasi $(Y)$.

\section{Analisis Koefisien Deter- minasi}

Analisis determinasi digunakan untuk mengetahui besarnya prosentase pengaruh variabel bebas secara bersama-sama dengan variabel terikat.

Berdasarkan output tabel Model Summary, dapat dilihat bahwa nilai R Square yang diperoleh sebesar 0,537 atau $53,7 \%$. Hal ini menunjukkan bahwa presentase pengaruh variabel bebas, yakni konflik peran dan stres kerja terhadap komitmen organisasi adalah $53,7 \%$.

\section{KESIMPULAN DAN IMPLIKASI Kesimpulan}

Berdasarkan hasil penelitian yang dilakukan dengan judul Pengaruh Konflik Peran dan Stres Kerja Terhadap Komitmen Organisasi di Rumah sakit Tk IV Salak Bogor, maka peneliti menyimpulkan bahwa:

1. Adanya pengaruh yang signifikan konflik peran terhadap komitmen organisasi, artinya jika konflik peran meningkat maka komitmen organisasi akan mengalami penurunan.

2. Adanya pengaruh yang signifikan stres kerja terhadap komitmen organisasi, artinya jika stres kerja meningkat maka komitmen organisasi akan mengalami penurunan.

3. Konflik peran dan stres kerja mempunyai pengaruh signifikan dengan komitmen organisasi.

\section{Implikasi}

Implikasi dari studi penelitian ini adalah agar pihak rumah sakit dapat memperhatikan segala faktorfaktor yang dapat mengurangi komitmen organisasi karyawan 
dalam hal ini perawat terhadap rumah sakit

Sumber daya yang berkualitas jika komitmen organisasinya juga kuat. Untuk itu maka organisai harus memperhatikan hal yang dapat mempengaruhi komitmen organisasi pada karyawannya. Dalam hal ini konflik peran yang terjadi pada perawat di Rumkit Salak tidak boleh dibiarkan begitu saja melainkan harus segera dikurangi atau bahkan dihilangkan. Konflik Peran meliputi pertentangan atas tuntutan, harapan dan kewajiban seorang karyawan. Selain itu adanya tekanan yang datang dari peran lain yang dijalankan secara bersamaan.

Dari kedua indikator tesebut, yang perlu diperhatikan oleh rumah sakit adalah indikator tekanan dari peran lain. Jadi diharapkan rumah sakit dapat lebih memperhatikan pembagian jam kerja, beban kerja dan keamanan bekerja bagi para perawatnya khususnya perawat wanita yang sudah menikah sesuai dengan penelitian ini, dimana mereka memiliki tugas tidak hanya sebagai perawat, melainkan juga sebagai istri dan ibu rumah tangga. Dengan jam kerja serta beban kerja yang lebih ringan, maka dari salah satu peran yang mereka jalankan tersebut tidak menimbulkan tekanan untuk peran lain yang juga sedang dijalankan. Apabila konflik peran dapat dikurangi, maka komitmen organisasi akan meningkat.

Selain itu pihak rumah sakit juga harus dapat memperhatikan tingkat stres kerja yang dialami para perawatnya. Stres kerja meliputi reaksi fisik, reaksi psikologis dan reaksi perilaku. Indikator dari stres yang perlu diperhatikan rumah sakit adalah reaksi fisik. Rumah sakit diharapkan dapat mengurangi berbagai tekanan pekerjaan kepada para perawatnya selama bertugas, yang dapat mengakibatkan stres kerja. Selain itu juga rumah sakit diharapkan dapat meningkatkan hubungan kerja baik antara atasan dengan bawahannya. Apabila stres kerja dapat dikurangi maka komitmen organisasi akan meningkat.

Namun komitmen organisasi tidak hanya dipengaruhi oleh dua faktor ini saja, melainkan masih ada faktor-faktor lain yang mampu meningkatkan komitmen organisasi, sehingga tidak menutup kemungkinan diadakan penelitian lanjutan untuk meneliti variabelvariabel yang mempengaruhi komitmen organisasi

\section{DAFTAR PUSTAKA}

Anatan, Lina \& Lena Ellitan. Manajemen Sumber Daya 
Manusia dalam Bisnis Modern.

Bandung: Alfabeta, 2009.

Assegaf, Yasmin Umar "Pengaruh Konflik Peran dan Stres Kerja Terhadap Komitmen Organisasl" , Jurnal Akuntansi \& Bisnis Vol 5, No.2, Agustus 2005.

Gibson, Ivancevich dan Donnely. Organisasi. Jilid II. Jakarta: Erlangga, 2005.

Daft, Richard L. Management. Jakarta: Salemba Empat,2006.

Gibson, dkk. Organisasi Jilid II, Jakarta: Erlangga, 2005.

Glissmeyer, Michael , dkk. "Role Conflict, Role Ambiguity, and Intention to Quit the Organization: The Case of Law Enforcement Officers

Greenberg, Jerald. Managing behavior in Organization. New jersey: Prentice Hall, inc,2003.

Malhotra, Sunita \& Sapna Sachdeva.

"Social Roles and Role Conflict: An Interprofessional Study Among Women", Journal of the Indian Academy of Applied Psychology Vol 31, No.1-2 Tahun 2005.

McShane \& Von Glinow. Organizational Behaviour.New York: McGraw Hill, 2009).
Newstrom, John. Organizational Behaviour: Human Behaviour at Work. New York: McGraw Hill,2007.

Rivai, Veithzal.Manajemen Sumber Daya Manusia.Jakarta: PT Raja Grafindo Perkasa, 2008.

Soetjipto, Budi Eko. "Model Struktural Pengaruh Konflik Peran, Kepuasan kerja dan Komitmen Organisasi terhadap niat untuk keluar",Jurnal IPS dan Pengajaran. Tahun 39, No.3, Juli 2005.

Suparwati. "Motivasi sebagai moderating variabel dalam hubungan antara komitmen dengan kepuasan kerja', Ventura, Vol 8, No.2, Desember 2005.

Umar, Husein. Desain Penelitian MSDM dan Perilaku Karyawan. Jakarta: Rajawali Pers, 2010

Usman, Ahmad dkk. "Work stress Experiences by the Teaching Staff of University of the Punjab, Pakistan: Antecedents and Consequences", International Journal of Business and Social Science, Vol.2 No.8, May 2011. 